\title{
The reaction products of sulfide and S-nitrosoglutathione are potent vasorelaxants
}

\author{
Andrea Berenyiova a , Marian Grman ${ }^{\mathrm{b}, \mathrm{c}}$, Ana Mijuskovic ${ }^{\mathrm{d}}$, Andrej Stasko ${ }^{\mathrm{e}}$, Anton Misak ${ }^{\mathrm{b}}$, \\ Peter Nagy ${ }^{\mathrm{f}}$, Elena Ondriasova ${ }^{\mathrm{g}}$, Sona Cacanyiova ${ }^{\mathrm{a}}$, Vlasta Brezova ${ }^{\mathrm{e}}$, Martin Feelisch ${ }^{\mathrm{h}}$, \\ Karol Ondrias b,* \\ a Institute of Normal and Pathological Physiology SAS, Sienkiewiczova 1, 81371 Bratislava, Slovakia \\ ${ }^{\mathrm{b}}$ Institute of Molecular Physiology and Genetics SAS, Vlarska 5, 83334 Bratislava, Slovakia \\ ' Center for Molecular Medicine SAS, Vlarska 7, 83101 Bratislava, Slovakia \\ d Institute for Biological Research “Siniša Stanković”, University of Belgrade, Blvd Despota Stefana 142, Belgrade, Serbia \\ e Faculty of Chemical and Food Technology, Slovak University of Technology, Radlinskeho 9, 81237 Bratislava, Slovakia \\ ${ }^{\mathrm{f}}$ Department of Molecular Immunology and Toxicology, National Institute of Oncology, Ráth György utca 7-9, Budapest, 1122 Hungary \\ ${ }^{g}$ Faculty of Pharmacy, Comenius University, Odbojarov 10, 83232 Bratislava, Slovakia

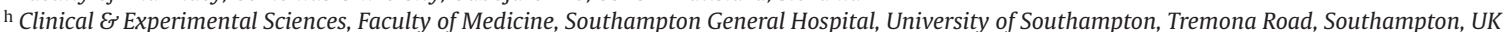

\section{A R T I C L E I N F O}

\section{Article history:}

Available online 18 December 2014

\section{Keywords:}

Hydrogen sulfide

Nitric oxide

Nitrosopersulfide

Polysulfides

Aorta relaxation

Uterus

\begin{abstract}
A B S T R A C T
The chemical interaction of sodium sulfide $\left(\mathrm{Na}_{2} \mathrm{~S}\right)$ with the NO-donor S-nitrosoglutathione (GSNO) has been described to generate new reaction products, including polysulfides and nitrosopersulfide ( $\left.\mathrm{SSNO}^{-}\right)$ via intermediacy of thionitrous acid (HSNO). The aim of the present work was to investigate the vascular effects of the longer-lived products of the Sulfide/GSNO interaction. Here we show that the products of this reaction relax precontracted isolated rings of rat thoracic aorta and mesenteric artery (but to a lesser degree rat uterus) with a $>2$-fold potency compared with the starting material, GSNO ( $50 \mathrm{nM})$, whereas $\mathrm{Na}_{2} \mathrm{~S}$ and polysulfides have little effect at $1-5 \mu \mathrm{M}$. The onset of vasorelaxation of the reaction products was 7-10 times faster in aorta and mesenteric arteries compared with GSNO. Relaxation to GSNO $(100-500 \mathrm{nM})$ was blocked by an inhibitor of soluble guanylyl cyclase, ODQ $(0.1$ and $10 \mu \mathrm{M})$, and by the

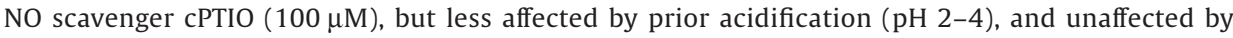
$\mathrm{N}$-acetylcysteine $(1 \mathrm{mM})$ or methemoglobin ( $20 \mu \mathrm{M}$ heme). By contrast, relaxation to the Sulfide/GSNO reaction products (100-500 $\mathrm{nM}$ based on the starting material) was inhibited to a lesser extent by ODQ only slightly decreased by CPTIO, more markedly inhibited by methemoglobin and N-acetylcysteine, and abolished by acidification before addition to the organ bath. The reaction mixture was found to generate $\mathrm{NO}$ as detected by EPR spectroscopy using $\mathrm{N}$-(dithiocarboxy)-N-methyl-D-glucamine $\left(\mathrm{MGD}_{2}\right)-\mathrm{Fe}^{2+}$ as spin trap. In conclusion, the Sufide/GSNO reaction products are faster and more pronounced vasorelaxants than GSNO itself. We conclude that in addition to $\mathrm{NO}$ formation from $\mathrm{SSNO}^{-}$, reaction products other than polysulfides may give rise to nitroxyl (HNO) and be involved in the pronounced relaxation induced by the Sulfide/GSNO cross-talk.
\end{abstract}

(C) 2014 Elsevier Inc. All rights reserved.
Abbreviations: ABS, absorbance; AS, Angeli's salt; AUC, area under the curve; cPTIO, 2-(4-carboxyphenyl)-4,4,5,5-tetramethylimidazoline-1-oxyl-3-oxide; GSNO, S-nitrosoglutathione; EPR, electron paramagnetic resonance; MGD, N-(dithiocarboxy)$\mathrm{N}$-methyl-D-glucamine; NAC, N-acetyl-L-cysteine; ODQ 1H-[1,2,4]oxadiazolo[4,3a]quinoxalin-1-one; Phen, (R)-(-)-phenylephrine hydrochloride; sGC, soluble guanylyl cyclase; $\mathrm{S}_{\mathrm{n}}$, polysulfides; SNP, nitroprusside; $\mathrm{SSNO}^{-}$, nitrosopersulfide.

* Corresponding author. Institute of Molecular Physiology and Genetics, Slovak Academy of Sciences, Vlarska 5, 83334 Bratislava, Slovak Republic. Fax: +421 2 54773666.

E-mail address: karol.ondrias@savba.sk(K. Ondrias).

\section{Introduction}

Endogenously synthesized hydrogen sulfide $\left(\mathrm{H}_{2} \mathrm{~S}\right)$ is recognized as an important gasotransmitter, which - similar to nitric oxide (NO) - influences many different biological processes [1]. Circulating and intracellular S-nitrosothiols, which are formed by the interaction of $\mathrm{NO}$ with thiol ( $\mathrm{SH}$ ) groups, act as an important bioreservoir for $\mathrm{NO}$ [2]. Similarly, $\mathrm{H}_{2} \mathrm{~S}$ can be stored in the form of sulfane sulfur and transported and released in response to a physiological stimulus [3]. A number of publications reported on the molecular interaction between $\mathrm{H}_{2} \mathrm{~S}$ and $\mathrm{NO}$ or NO-donors [4-14], and $\mathrm{H}_{2} \mathrm{~S}$ and NO were found to cooperatively regulate vascular tone by activating a neuroendocrine signaling pathway in which formation of 
nitroxyl (HNO) appears to play an important role [13]. Products of this $\mathrm{H}_{2} \mathrm{~S} / \mathrm{NO}$ interaction appear to have pronounced biological effects; however the nature of the reaction intermediates is currently unclear and many inconsistencies remain; for example, $\mathrm{H}_{2} \mathrm{~S}$ donors were found to either potentiate or attenuate relaxation effect of NO donors in isolated aortic rings in vitro $[15,16]$, or result in complete loss of vasodepressor activity in anesthetized rats [16]. $\mathrm{H}_{2} \mathrm{~S}$ was shown to relax uterus from pregnant [17,18] and non-pregnant rats [19], and sodium nitroprusside (SNP) prevented $\mathrm{H}_{2} \mathrm{~S}$ induced relaxation of rat uterus [20]. Thionitrous acid (HSNO) has been proposed to represent an important carrier of bioactivity of the interaction of S-nitrosothiols with $\mathrm{H}_{2} \mathrm{~S}$ [10], but the evidence provided appears to be inconsistent with the known chemical properties of HSNO. Moreover, HSNO would be expected to rapidly react with excess sulfide to form other species; thus its biological effect would be very short-lived. Cortese-Krott and coworkers [12] observed that sulfide reacts with S-nitrosothiols to form multiple bioactive products, and proposed that nitrosopersulfide (SSNO-; $\lambda_{\max } 412 \mathrm{~nm}$ in aqueous buffers, $\mathrm{pH}$ 7.4) accounts for some of the longer-lived effects of this interaction. $\mathrm{SSNO}^{-}$generated both $\mathrm{NO}$ and polysulfides on decomposition, resulting in sustained potentiation of nitrosothiolinduced soluble guanylate cyclase (sGC) stimulation. While individual reaction product(s) have not yet been unequivocally identified it would appear to be important to further characterize the bioactivity of key reaction products of the interaction of nitrosothiols and sulfide in intact tissue preparations.

In the present work we followed the procedure of CorteseKrott et al. [12] to prepare longer-lived products of the Sulfide/ GSNO interaction by pre-incubating sodium sulfide $\left(\mathrm{Na}_{2} \mathrm{~S}\right)$ with the NO donor GSNO. Reaction products may include SSNO-', polysulfides and possibly other species [12], but short-lived reaction intermediates can be safely excluded from contributing to the bioactivity of the mixture following this route of preparation. Polysulfides have recently been shown to exert potent biological effects on a number of targets that may explain, at least in part, some of the effects of endogenously produced $\mathrm{H}_{2} \mathrm{~S}$ and those observed with pharmacological sources of $\mathrm{H}_{2} \mathrm{~S}[21-23]$. The aim of the present studies was to evaluate the biological action profile of the reaction products of the Sulfide/GSNO interaction in vascular tissue; this was accomplished by comparing the vasoactive effects of the Sulfide/ GSNO products with that of GSNO, $\mathrm{Na}_{2} \mathrm{~S}$ and polysulfides in two functionally distinct smooth muscle preparations, uterus strips and rat thoracic aorta (and mesenteric arteries). The former are characterized by phasic spontaneous contractions with spike-like changes in membrane potential, while the latter develops tonic contractions associated with gradual changes in membrane potential when stimulated by vasoconstrictors [24]. It was shown that rat uterus is less sensitive to NO than rat aorta; about 10,000-fold less nitroprusside (SNP) is required to relax aorta in comparison with rat uterus [25]. This is consistent with a higher sensitivity to diethylamine-NO and nitroglycerine in aorta compared with rat uterus [24].

\section{Materials and methods}

\subsection{Chemicals}

All chemicals were purchased from Sigma-Aldrich. Hemoglobin from bovine blood (Sigma H2500), comprising mostly metHb, was used as received. $\mathrm{Na}_{2} \mathrm{~S} \bullet 9 \mathrm{H}_{2} \mathrm{O}$ (Aldrich, 431648) was used as $\mathrm{H}_{2} \mathrm{~S}$ donor, which dissociates in solution and reacts with $\mathrm{H}^{+}$to yield $\mathrm{HS}^{-}, \mathrm{H}_{2} \mathrm{~S}$ and a trace of $\mathrm{S}^{2-}$ [26]. We use the term 'sulfide' to encompass the total mixture of $\mathrm{H}_{2} \mathrm{~S}, \mathrm{HS}^{-}$and $\mathrm{S}^{2-}$. $\mathrm{Na}_{2} \mathrm{~S} \bullet 9 \mathrm{H}_{2} \mathrm{O}$ was washed in distilled $\mathrm{H}_{2} \mathrm{O}$ and then dissolved in $\mathrm{H}_{2} \mathrm{O}$ to give a stock solution of $\sim 100 \mathrm{mM}$, which was determined by the absorbance (ABS) at $\lambda_{\max } 232 \mathrm{~nm}, \varepsilon=7700$. The concentration of polysulfides in this stock was $<10 \mu \mathrm{M}$ as judged by UV-VIS spectrophotometry [26]. This stock solution was always prepared fresh right before the experiment, kept in sealed vials with minimal headspace and used within 4 hours. The products of the Sulfide/GSNO interaction were prepared by mixing equal volumes of $20 \mathrm{mM} \mathrm{Na}_{2} \mathrm{~S}$ with $2 \mathrm{mM}$ GSNO in $50 \mathrm{mM}$ Tris- $\mathrm{HCl}$ buffer, $7.4 \mathrm{pH}$, at $21 \pm 2{ }^{\circ} \mathrm{C}$, resulting in a final $\mathrm{pH}$ of 8-9. No qualitative difference in vasorelaxant properties of the reaction mixture was seen when prepared in more concentrated buffer systems according to Cortese-Krott et al. [12]. Product formation was followed by UV-VIS spectroscopy (absorbance increase at $\lambda_{\max } 412 \mathrm{~nm}$ ), and reaction was complete within $3 \mathrm{~min}$, by which time the products were diluted to the final concentration in Tris- $\mathrm{HCl}$ buffer and added to the organ bath; $\mathrm{pH}$ in the organ bath was kept constant at 7.4. Since SSNO- was proposed to be a major longer-lived product of the sulfide and S-nitrosothiols reaction [12] and no further efforts were made to separate individual products of the Sulfide/GSNO interaction, we hereinafter refer to the products of the reaction mixture as the 'SSNO- mix'. The concentration of the products is defined as the concentration of GSNO in the mixture at time zero.

Since for the preparation of the 'SSNO- mix', a 10:1 molar excess of $\mathrm{Na}_{2} \mathrm{~S}$ over GSNO was used, polysulfides were also prepared at a 10:1 sulfide/HOCl molar ratio. Polysulfides were prepared by interaction of $\mathrm{Na}_{2} \mathrm{~S}$ with $\mathrm{HOCl}$ according to Nagy and Winterbourn [27]. In the experiments with uterus, $500 \mu \mathrm{l}$ of $5 \mathrm{mM}$ of $\mathrm{HOCl}$ (prepared in $100 \mathrm{mM} \mathrm{NaOH}$ ) were mixed with $500 \mu \mathrm{l}$ of $50 \mathrm{mM}$ of sulfide (prepared from $\mathrm{Na}_{2} \mathrm{~S} \bullet 9 \mathrm{H}_{2} \mathrm{O}$ in ultrapure deionized water). To avoid overoxidation of sulfide by $\mathrm{HOCl}, \mathrm{HOCl}$ was slowly dropped into the vortexed sulfide solution. This system generated $2.5 \mathrm{mM}$ sulfane sulfur (in the form of inorganic polysulfides, $S_{n}$ ), with the remainder being free sulfide $(\sim 20 \mathrm{mM})$. The sulfide/ $S_{\mathrm{n}}$ solution was immediately applied after the preparation. In the case of experiments with aortic rings, $500 \mu \mathrm{l}$ of $1 \mathrm{mM}$ of $\mathrm{HOCl}$ were mixed with $500 \mu \mathrm{l}$ of $10 \mathrm{mM}$ of sulfide. This system generated $0.5 \mathrm{mM} \mathrm{S}_{\mathrm{n}}$, with the rest of the sulfur content remaining as free sulfide $(\sim 4 \mathrm{mM})$. We refer to the $S_{n}$ concentration as the concentration of added $\mathrm{HOCl}$ in the sulfide $/ S_{n}$ mixture.

\subsection{Measurement of uterus contractility}

All protocols for handling rats were approved by the Local Animal Care Committee of the Institute for Biological Research (Belgrade, Serbia). Experiments were carried out as previously described [19]. Briefly, virgin female Wistar rats ( 225 grams, 10-12 weeks of age) were used in these experiments. Female rats were staged in their estrous cycle, as determined by examination of a daily vaginal lavage [28]. The uterine horns were mounted separately for recording of isometric tension in De Jalon's solution containing (in $\mathrm{mM}$ ): $\mathrm{NaCl}$ $154, \mathrm{KCl} 5.64, \mathrm{NaHCO}_{3} 5.95, \mathrm{CaCl}_{2} 0.41$ and glucose 2.77, maintained at $37{ }^{\circ} \mathrm{C}$ and aerated with a gas mixture of $95 \%$ oxygen/5\% carbon dioxide. Changes in isometric force were recorded on a TSZ04-E Tissue Bath System (Experimetria, Budapest, Hungary). Uteri were allowed to stabilize during 1 hour, under $1 \mathrm{~g}$ initial tension. Effects of sulfide, GSNO, $\mathrm{S}_{\mathrm{n}}$ and the 'SSNO- mix' were obtained by adding the respective test agents directly to the organ bath. The effects of each compound on the area under the curve (AUC) and frequency were analyzed for $\sim 5$ min before and $\sim 5$ min after administration. If no peaks after the administration were observed, we evaluated recordings for 5 min after compound addition. The effect was compared with control values that were measured $\sim 5$ min before administration and set as $100 \%$. Results are expressed as mean \pm SEM of $n$ experiments. Normality of the data was tested using the Shapiro-Wilk test and quantile-quantile plots. Particular statistical analyses are described in the figure legends. $P$ values less than 0.05 were considered to be statistically significant. 


\subsection{Measurement of rat aorta contractility}

All procedures were approved by the State Veterinary and Food Administration of the Slovak Republic. Experiments were carried out as previously described $[8,9]$. Briefly, preparations of thoracic aorta and arteria mesenterica superior (main branch) were prepared from male Wistar rats and mounted for recording of isometric tension changes in oxygenated $\left(95 \% \mathrm{O}_{2} / 5 \% \mathrm{CO}_{2} ; 37{ }^{\circ} \mathrm{C}\right) \mathrm{Krebs}-$ bicarbonate solution comprising (in $\mathrm{mM}$ ) $118 \mathrm{NaCl}, 5 \mathrm{KCl}, 25 \mathrm{NaHCO}_{3}$, $1.2 \mathrm{MgSO}_{4}, 1.2 \mathrm{KH}_{2} \mathrm{PO}_{4}, 2.5 \mathrm{CaCl}_{2}, 11$ glucose, $0.032 \mathrm{CaNa}_{2} \mathrm{EDTA}, \mathrm{pH}$ 7.5. After equilibration and repeated adjustment of passive tension rings were precontracted by $1 \mu \mathrm{M}$ phenylephrine (Phen) to achieve submaximal contraction; a stable contraction level was reached typically 30-45 min after Phen, which was taken as $100 \%$ contraction ( $=0 \%$ relaxation). The effects of GSNO, sulfide, $\mathrm{S}_{\mathrm{n}}$, and the 'SSNO- mix' were calculated as \% relaxation from the pre-contraction level. Results are expressed as mean \pm SEM of $n$ experiments. Normality of the data was tested using the Shapiro-Wilk test and quantile-quantile plots. Particular statistical analyses are described in the figure legends. $P$ values less than 0.05 were considered to be statistically significant.

\subsection{EPR measurements}

To test whether or not the products of the Sulfide-GSNO interaction release NO, electron paramagnetic resonance (EPR) measurements were carried out using $\mathrm{N}$-(dithiocarboxy)-N-methylD-glucamine (MGD)/Fe ${ }^{2+}$ as a spin trap. The $\mathrm{MGD}_{2} / \mathrm{Fe}^{2-}$ spin trap solution ( $5 \mathrm{mM}$ MGD; $1 \mathrm{mM} \mathrm{FeSO}_{4}$ in $50 \mathrm{mM}$ Tris-HCl buffer, $\mathrm{pH} 7.4$ $\mathrm{pH}$ ) was prepared freshly right before the experiments [29]. $\mathrm{MGD}_{2} \mathrm{Fe}^{2+}$ displays a characteristic three-line EPR spectrum after NO binding. EPR spectra were measured on a Bruker EMX spectrometer (flat cell, X-band $~ 9.4 \mathrm{GHz}$, central field $336 \mathrm{mT}, 10$-mW microwave power, $0.05 \mathrm{mT}$ modulation amplitude, $0.64 \mathrm{~ms}$ time constant, $6 \mathrm{mT}$ scan range, $40 \mathrm{~s}$ scan time) at a temperature of $20^{\circ} \mathrm{C}$. The 'SSNO- mix' was directly added to the spin trap solution and EPR spectra were measured within approx. 3 min.

\section{Results and discussion}

\subsection{Formation and stability of Sulfide/GSNO reaction products}

Fig. 1A shows the UV-VIS spectral characteristics of the compounds $\mathrm{Na}_{2} \mathrm{~S}, \mathrm{GSNO}$ and their reaction products as used in our study. The spectra of the individual starting materials, $\mathrm{Na}_{2} \mathrm{~S}$ and GSNO rapidly changed immediately after mixing, and the products revealed a new absorbance feature at $\lambda_{\max } 412 \mathrm{~nm}$ (yellow product), we assign to represent nitrosopersulfide $\left(\mathrm{SSNO}^{-}\right)$[5,6,12]. A broad absorption band at $260-360 \mathrm{~nm}$ was assigned to belong to $\mathrm{S}_{\mathrm{n}}$, also known to be formed in the reaction [12]. After addition of $\mathrm{HCl}$ to the product mixture, which decreased pH from 7.4 to $2-4$, the peak at $\lambda_{\max } 412 \mathrm{~nm}$ disappeared within less than $1 \mathrm{~min}$ [11,12]. The spectra are similar to those in our previous reports using Sulfide/GSNO at different molar ratios and using S-nitrosopenicillamine as NO-donor [11,12]. The same UV-VIS absorbance features were used to study precursor and product stabilities. GSNO $\left(\lambda_{\max } 334 \mathrm{~nm}\right)$ absorbance did not change over time, but that of $\operatorname{SSNO}^{-}\left(\lambda_{\max } 412 \mathrm{~nm}\right)$ decreased slowly in oxygen/ carbon dioxide gassed Krebs-bicarbonate solution to $80 \%$ of maximal absorbance over $20 \mathrm{~min}$ (Fig. 1B), indicative of its tendency to slowly decompose in the organ bath solution.

\subsection{Effects of sulfide, GSNO, $S_{n}$ and the 'SSNO- mix' on uterus contractility}

Sulfide (100 and $200 \mu \mathrm{M}$ ) significantly decreased AUC and frequency of uterine contraction, whereas GSNO (10 and $20 \mu \mathrm{M})$ had considerably weaker effects (Fig. 2). Interestingly enough, the
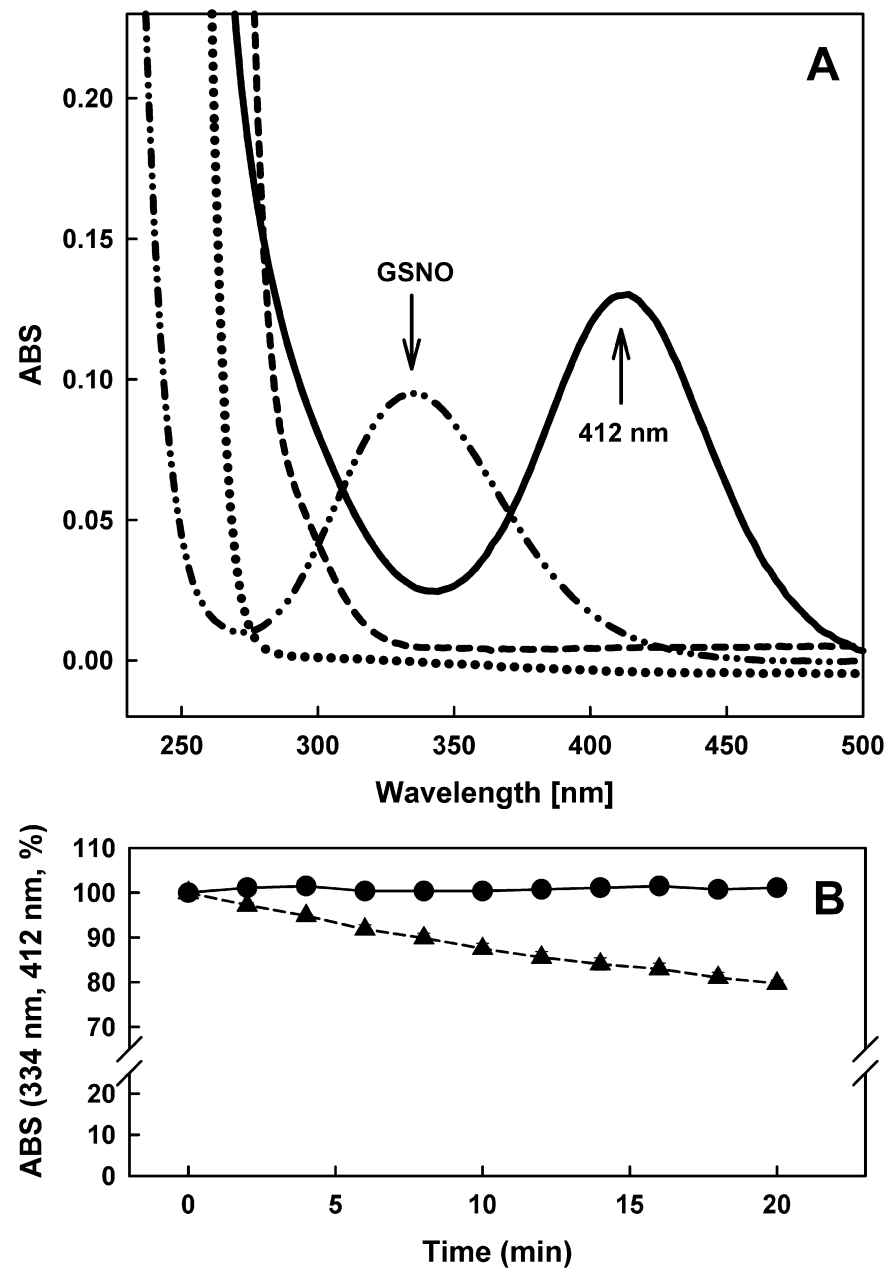

Fig. 1. (A) The UV-VIS absorption spectra of $1 \mathrm{mM} \mathrm{Na}_{2} \mathrm{~S}$ (dotted), $0.1 \mathrm{mM} \mathrm{GSNO}$ (dashdotted), the mixture of $\mathrm{Na}_{2} \mathrm{~S}$ and GSNO after 3 min incubation (the 'SSNO'- mix'; full) and after addition of $\mathrm{HCl}$ to decrease $\mathrm{pH}$ from 7.4 to 2-4 (dashed line). Buffer: $50 \mathrm{mM}$ Tris- $\mathrm{HCl}, \mathrm{pH}$ 7.4. ABS - absorbance. (B) Time-dependent changes in absorbance of GSNO ( $\lambda_{\max } 334 \mathrm{~nm} ; 100 \mu \mathrm{M}$, circles-full line) and the Sulfide/GSNO product, SSNO- $^{-}$ ( $\lambda_{\max } 412 \mathrm{~nm}, 100 \mu \mathrm{M}$, triangles-dash line) in $\mathrm{O}_{2} / \mathrm{CO}_{2}$ bubbled Krebs-bicarbonate buffer $(n=3)$.

products of the reaction mixture (Sulfide/GSNO 100/10 $\mu \mathrm{M}$ ) were found to exert only minor effect on both contraction and frequency; when compared at equimolar concentration with regard to sulfide the effects of the reaction products (Sulfide/GSNO $=200 / 20 \mu \mathrm{M}$ ) were significantly lower than with $200 \mu \mathrm{M}$ sulfide alone (Fig. 2B,C). These results are in accordance with the observation that the NO donor SNP prevented $\mathrm{H}_{2} \mathrm{~S}$-induced relaxation of rat uterus, an effect that was attributed to the generation of nitroxyl (HNO) [20]. Recently, it was reported that relaxation effects of neutral and anionic forms of sulfide $\left(\mathrm{H}_{2} \mathrm{~S} / \mathrm{HS}^{-}\right)$differ in quality and the inhibition of uterine contractility might be a consequence of the specific actions of $\mathrm{HS}^{-}$ in relation to its negative charge [19]. Our results of less significant effects of the reaction products by comparison with sulfide indicate that the Sulfide/GSNO interaction diminishes the relaxing effects of sulfide, even at a Sulfide/GSNO molar ratio of 10/1. Since the first application of sulfide on uterus strips had less relaxation effect than the second and third application (Fig. 2D), we compared effects of sulfide and $S_{n}$ at these subsequent applications. There was no significant difference between the relaxation effect of sulfide in the presence and absence of $S_{n}$ applied as the first or third addition (Fig. 2D). In summary, sulfide exerts powerful inhibitory effects on uterine smooth muscle, which appear to 

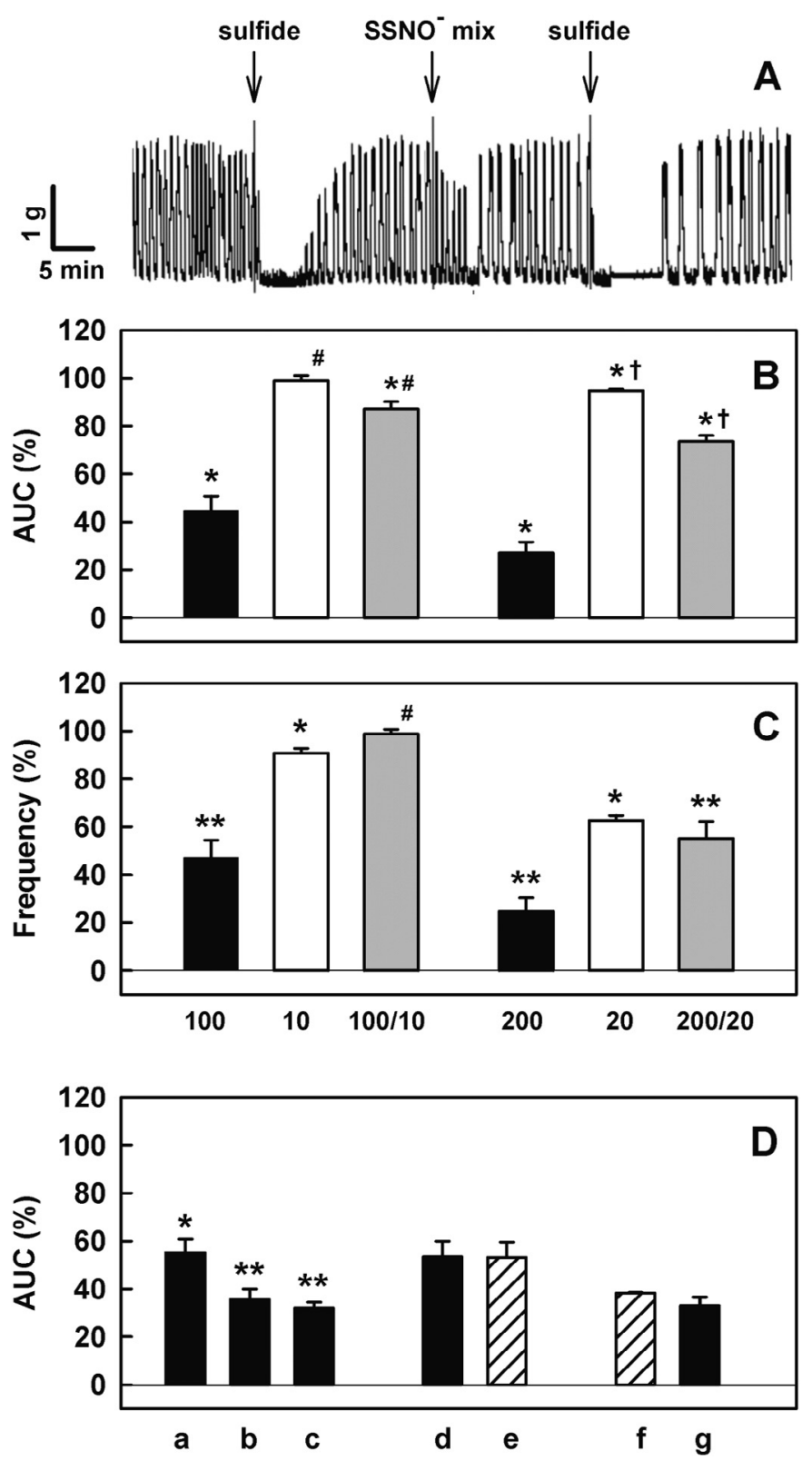

Fig. 2. Effect of sulfide, GSNO, the 'SSNO- mix' and $\mathrm{S}_{\mathrm{n}}$ on uterine contractility. Representative isometric recordings of calcium contracted rat uterine strips; comparison of the effects of sulfide $(200 \mu \mathrm{M})$, the 'SSNO- mix' (Sulfide/GSNO 200/20 $\mu \mathrm{M}$ ) and again sulfide $(200 \mu \mathrm{M})(\mathrm{A})$. Effects of sulfide (100 and $200 \mu \mathrm{M}$, black), GSNO (10 and $20 \mu \mathrm{M}$, white) and the 'SSNO- mix' (Sulfide/GSNO 100/10 and 200/20 $\mu \mathrm{M}$, gray) on the area under the curve (AUC) (B) and frequency (C). Effects of three consequent additions of sulfide (D, a, b, c, $100 \mu \mathrm{M})$ alone, and comparison of sulfide (d, $100 \mu \mathrm{M})$ with sulfide $/ S_{n}(e, 100 / 12.5 \mu M)$ at the first addition and sulfide $/ S_{n}(f, 100 / 12.5 \mu M)$ with sulfide $(\mathrm{g}, 100 \mu \mathrm{M})$ at the third addition. The values represent decrease of the parameters to given \% versus $100 \%$ of control. Nonparametric Skillings-Mack's statistical test, followed by the Dwass-Steel-Chritchlow-Fligner's test was used to compare effects of sulfide, GSNO and the 'SSNO- mix' versus control (B, C), ${ }^{*} P<0.05$, ${ }^{* *} P<0.01$; effects of the 'SSNO' ${ }^{-} \mathrm{mix}^{\prime}(10 \mu \mathrm{M})$ and GSNO $(10 \mu \mathrm{M})$ versus sulfide $(100 \mu \mathrm{M})(\mathrm{B}, \mathrm{C}),{ }^{\#} P<0.05$; and effects of the 'SSNO- mix' $(20 \mu \mathrm{M})$ and GSNO $(20 \mu \mathrm{M})$ versus sulfide $(200 \mu \mathrm{M})(\mathrm{B}, \mathrm{C}),{ }^{\dagger} P<0.05$. Friedman's statistical test, followed by Conover's test was used to compare effects of subsequent sulfide additions versus control (D), ${ }^{*} P<0.05$, ${ }^{* *} P<0.01$. Wilcoxon's test was used to compare effects of sulfide $(100 \mu \mathrm{M})$ versus sulfide $/ S_{\mathrm{n}}(12.5 \mu \mathrm{M})(\mathrm{D})$.

be unaffected by the presence of $S_{n}$ but are diminished by interaction with NO-donors such as nitrosothiols. These findings suggest that $S_{n}$ play less prominent roles in relaxing uterine tissue compared with sulfide alone, and that the interaction of sulfide with
NO attenuates sulfide's inhibitory action. Considering that sulfide may be produced from cystathionine- $\gamma$-lyase (CSE) in utero NO might be expected to play a suppressor role by modulating sulfide's action on uterus contraction [30].

To evaluate whether the results observed in uterus strips are representative of smooth muscle in general, we used two different vascular preparations in the next part of our investigation. Since aortic smooth muscles are functionally distinct and more sensitive to NO than uterine muscles [25], we compared the effects of sulfide, $\mathrm{S}_{\mathrm{n}}$, GSNO and the 'SSNO- mix' on rat aortic strips.

\subsection{Effects of sulfide, GSNO, $S_{n}$ and the 'SSNO- mix' on aortic contractility}

An example of the relaxing effects of GSNO and the 'SSNO- mix' in phenylephrine $(1 \mu \mathrm{M})$ precontracted rat aortic ring is shown in Fig. $3 \mathrm{~A}$ and $\mathrm{B}$. The relaxation effect of the ' $\mathrm{SSNO}^{-}$mix' was significantly pronounced, faster and shorter lasting when compared with GSNO in both, aortic and mesenteric rings (Fig. 3). The relaxation effect of the 'SSNO'- mix' ( $50 \mathrm{nM}$ ) on mesenteric artery was 2.6 times more powerful than that of GSNO (50 nM) (Fig. 4g,p). The time required for relaxation to return to $50 \%$ of its maximal effect was $5.5 \pm 0.5 \mathrm{~min}$ and $>10 \mathrm{~min}$ for the 'SSNO'- mix' compared with GSNO itself (100 nM). Since $\sim 90 \%$ of $\mathrm{SSNO}^{-}$was still present in the bath solution during the decay phase (Figs $3 \mathrm{~A}, 5 \mathrm{~A}, \mathrm{~B}$ ), we may assume that a product(s) within the 'SSNO- mix' other than NO must be responsible for the tachyphylaxis to the initial vasorelaxation observed. A similar reversal of the relaxation has been reported for other compounds (including nitroglycerine, mastoparan and exogenous NO) and suggested to involve different pathways in addition to sGC desensitization [31-34]. The relaxation was fitted by a simple exponential decay function, $\mathrm{F}=\mathrm{y} 0+\mathrm{a}^{*} \exp \left(-\mathrm{b}^{*} \mathrm{x}\right)$ (Fig. 3C). The speed of relaxation triggered by the 'SSNO- mix' (50 nM) was 7.0 and 10.7 times faster for rat thoracic aorta and mesentericum, respectively, when compared with GSNO ( $50 \mathrm{nM})$. The average absolute values of $\tau_{1 / 2}$ for the induced relaxation by the 'SSNO- mix' and GSNO (50 nM) were 13 and $91 \mathrm{~s}$, respectively (Fig. 3D). These half-lives represent considerably faster reactions than the measured decomposition rates for either $\mathrm{SSNO}^{-}$in the 'SSNO- mix' $\left(\lambda_{\max }\right.$ $412 \mathrm{~nm}$ ) or GSNO ( $\lambda_{\max } 334 \mathrm{~nm}$ ) in gassed Krebs-bicarbonate buffer (Fig. 1B). The divergence between the rates of decomposition and speed of relaxation (compare Figs $1 \mathrm{~B}, 3$ and $5 \mathrm{C}$ ) suggests the involvement of an unknown enzymatic/non-enzymatic component within the vasculature that promotes NO release from GSNO and its reaction products with sulfide in situ; however, we cannot exclude at this juncture that a reaction product other than NO (e.g. SSNO-, HNO) directly triggers vasorelaxation. The surprisingly good fit of the time-dependent relaxation of the reaction products by the simple exponential decay function (Figs 3 C and $5 C$ ), however, suggests an interaction of a single component of the 'SSNO- mix' with (a) target(s) in vascular smooth muscle.

Thus, sulfide and GSNO have different effects on uterine and vascular smooth muscle, and either action appears to be different to that of the reaction products of the Sulfide/GSNO interaction (Figs 2, 3 ). The mechanisms of contraction and relaxation between uterus and aorta differ. It was reported that SNP prevented $\mathrm{H}_{2} \mathrm{~S}$ induced relaxation of rat uterus, and this effect was attributed to the generation of nitroxyl (HNO) [20]. From the different sensitivities of rat uterus and aorta to NO [25], it was suggested that an activation of sGC, a key mechanism for vasorelaxation in many non-uterine smooth muscle such as aortic tissue, may not be involved in uterine relaxation [35]. The results of the present study suggest that the products of the Sulfide/GSNO interaction may play an important role in muscle in which activation of sGC is involved in regulating their tonicity. 

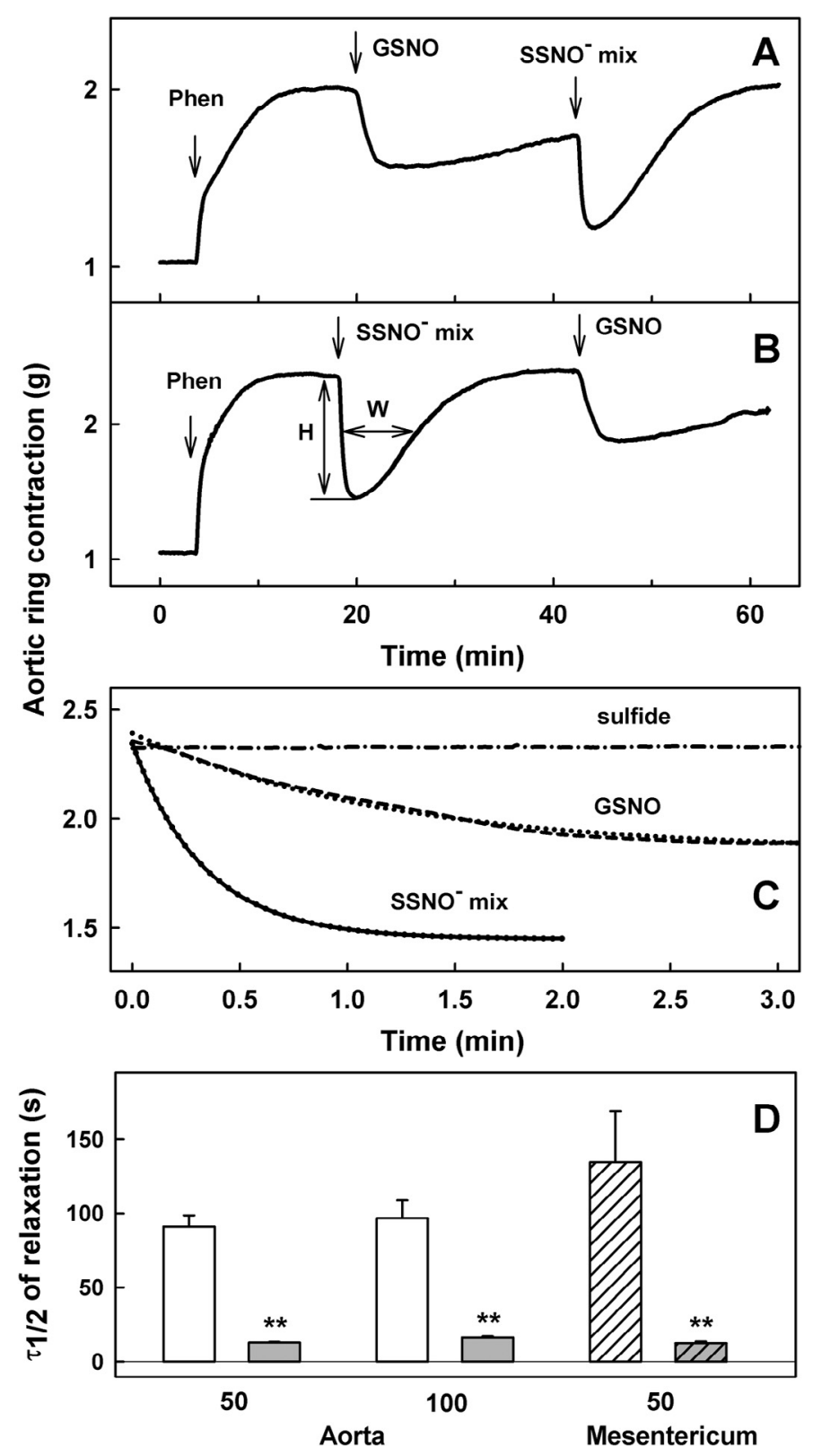

Fig. 3. Representative time-dependent relaxation effects of GSNO ( $100 \mathrm{nM})$, the 'SSNO mix' (100 nM) and sulfide ( $1 \mu \mathrm{M})$ on phenylephrine (Phen) precontracted rat aortic rings ( $\mathrm{A}, \mathrm{B}, \mathrm{C})$. $\mathrm{H}$ denotes height (=extent of relaxation) whereas $\mathrm{W}$ indicates the width, i.e. the time required for relaxation to return to $50 \%$ of the maximum. Timedependent relaxation fitted the simple exponential decay function, $\mathrm{F}=\mathrm{y} 0+$ $a^{*} \exp \left(-b^{*} \mathrm{x}\right)$, for the 'SSNO- mix' (experiment - full, fit - dotted) and for GSNO (experiment - dash, fit - dotted) (sulfide at $1 \mu \mathrm{M}$ had not effect) (C). The time to reach $50 \%$ of relaxation ( $\tau_{1 / 2}$ ) by GSNO (open bars) and (gray bars) at 50 and $100 \mathrm{nM}$ in aorta and in mesenteric rings at $50 \mathrm{nM}$ (coarse) (D). ${ }^{* *} \mathrm{P}<0.01$ indicates comparison of the effect of the 'SSNO- mix' versus GSNO (unpaired $t$ test).

In order to investigate the possible involvement of sulfide or $S_{n}$ in the relaxation effects of the ' $\mathrm{SSNO}{ }^{-}$mix', a sulfide $/ \mathrm{S}_{\mathrm{n}}$ mixture mimicking the concentrations in the $\mathrm{SSNO}^{-}$containing reaction solution was prepared. Sulfide and sulfide/ $S_{n}(1,2$ and $5 \mu \mathrm{M}$ of the original $\mathrm{Na}_{2} \mathrm{~S}$ concentration) had minor non-significant effects on vascular tone in aortic rings (Fig. 4), demonstrating that neither the excess sulfide nor the oxidation products can account for the pronounced relaxation induced by the products of the Sulfide/GSNO interaction. Our findings are in agreement with other reports showing that low $\mu \mathrm{M}$ concentrations of sulfide neither relax pre-constricted mouse aortic strips [36] nor human lobar pulmonary arteries [37].
sGC is a key enzyme of the NO signaling pathway. On binding of NO to the prosthetic heme group on SGC, the enzyme catalyzes the synthesis of the second messenger cGMP which induces vasorelaxation [38]. To confirm the suspected involvement of the $\mathrm{NO} / \mathrm{sGC}$ signaling pathway in the relaxation effect of the 'SSNO- mix', the SGC inhibitor ODQ was applied 15 min before addition of the contractile agonist. The effects of GSNO and the 'SSNO'- mix' were compared in the absence and presence of ODQ at $10 \mu \mathrm{M}$ and $100 \mathrm{nM}$ concentrations. Vasorelaxation of GSNO and the 'SSNO- mix' (100-500 nM) was virtually eliminated by $10 \mu \mathrm{M}$ ODQ confirming the involvement of the sGC signaling pathway mediating relaxation (data not shown). Much lower concentrations of ODQ $(100 \mathrm{nM})$ inhibited the relaxation of equipotent concentrations of GSNO $(1 \mu \mathrm{M})$ and the 'SSNO' mix' (100 nM) to a similar extent (Fig. 4). These results indicate that the active component(s) of the SulfideGSNO interaction is/are membrane-permeable and may release NO more efficiently than GSNO; alternatively, the reaction products may have a higher affinity for SGC without releasing free NO.

\subsection{Modulation of the relaxation effect of the 'SSNO- mix' and GSNO}

To evaluate the importance of NO in the observed relaxation effects (Figs 3 and 4), the NO scavenger 2-(4-carboxyphenyl)-4,4,5,5tetramethylimidazoline-1-oxyl-3-oxide (cPTIO) was applied [39]. cPTIO $(100 \mu \mathrm{M})$ alone had no effect on basal vascular tone, but significantly increased contraction in the presence of phenylephrine (Fig. 5A and B). These effects are identical to those of the NOscavenger oxyhemoglobin, which increases vascular contractile tone only following agonist-induced precontraction [40] and consistent with the notion that endothelial NO synthase activity is upregulated in the presence of contractile agonists. The level of maximal contraction achieved with CPTIO was comparable with that of the NOS-inhibitor, L-nitro-L-arginine (not shown); thus, the additional contraction observed upon addition of CPTIO is due to the scavenging of basal NO release from the endothelium. Although cPTIO is membrane-impermeable [41,42] its efficiency as an extracellular NO oxidant provides a large enough sink for NO to interfere with vascular tone.

The relaxation effect of GSNO (100 nM) was effectively inhibited by excess cPTIO ( $100 \mu \mathrm{M}$; Fig. 5), indicating that GSNO acts almost exclusively via releasing NO. On the contrary, relaxation induced by the 'SSNO- mix' ( $100 \mathrm{nM})$ was not inhibited by the presence of CPTIO, regardless of whether it was added before or after Phen (Fig. 5). These results indicate that a significant portion of the relaxation induced by these reaction products is mediated by an alternative mechanism, which may directly activate sGC without releasing free NO. These effects of CPTIO and ODQ on the products of the Sulfide/GSNO interaction are reminiscent of reports on effects of the HNO donor Angeli's salt (AS) [43-45]. This suggests that HNO may be involved in the relaxation effects induced by the ' $\mathrm{SSNO}^{-}$mix'. Similar to other HNO donors, AS is known to induce vasorelaxation in an NO/sGC-dependent fashion following oxidation $[46,47]$.

It was reported that in the presence of N-acetylcysteine (NAC), the thiol reacts with $\mathrm{HNO}$, thereby reducing the relaxation effect of HNO on precontracted rat aorta [48]. Hemoproteins are known to react with $\mathrm{HNO}$ to generate the corresponding nitrosyl adducts [49]. To test the assumption that vasorelaxation of the 'SSNO- mix' is, at least in part, mediated by the release of nitroxyl additional experiments were carried out with the HNO scavengers, methemoglobin $(20 \mu \mathrm{M}$ heme) and (NAC, $1 \mathrm{mM})$ [47]. The vasodilator effects of GSNO were not significantly influenced by NAC, but relaxation to the 'SSNO- mix' was significantly attenuated by NAC (Fig. 5D). Whereas the relaxation effects of GSNO was not significantly influenced by metHb (which is a very inefficient NO scavenger), that of the SSNO- mix' was partially inhibited (Fig. 5). 


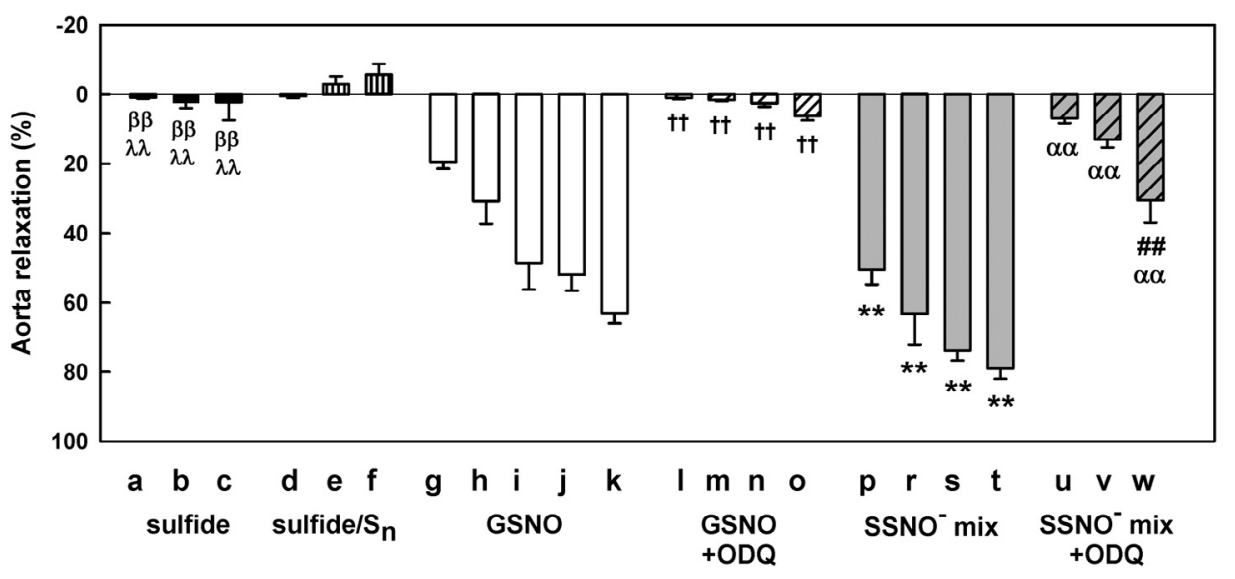

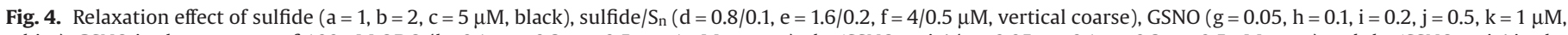

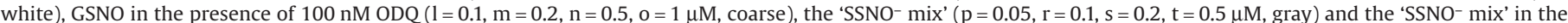

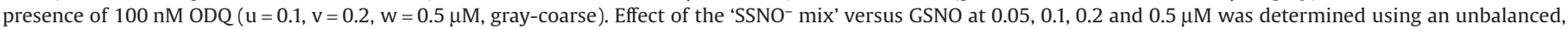

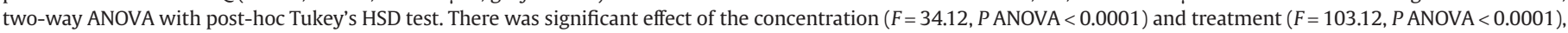

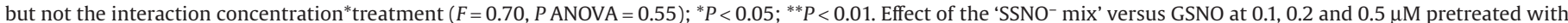

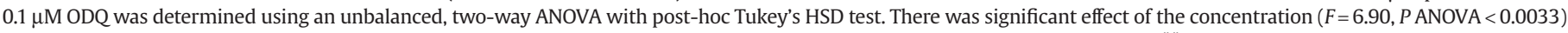

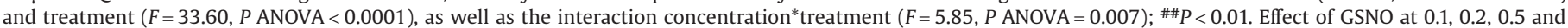

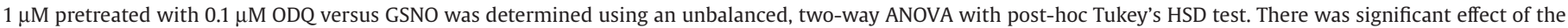

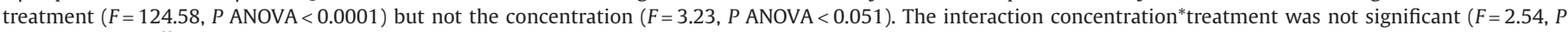

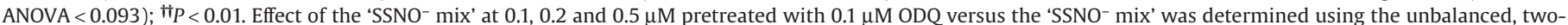

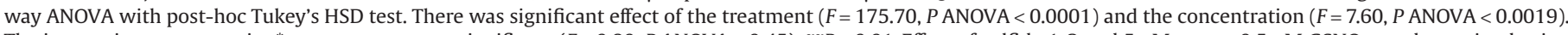

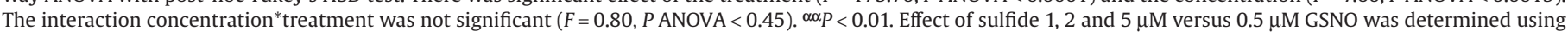

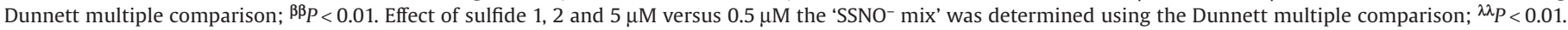

Our results are consistent with the view that a component of the products of the Sulfide/GSNO interaction is capable of releasing HNO.

Since acidification of the reaction mixture caused rapid decomposition of $\mathrm{SSNO}^{-}$(Fig. 1A [11,12];), the effect of such a pH adjustment on vasorelaxation was studied in isolated aortic rings. The relaxation effect of the Sulfide/GSNO products vanished when $\mathrm{HCl}$ was added to the reaction mixture before application to the organ bath. By contrast, the relaxation effect of GSNO was only slightly affected by acidification (Fig. 5). Taken together, these results clearly demonstrate that the reaction product with an absorption maximum at $412 \mathrm{~nm}$ (assigned by us as nitrosopersulfide) accounts for the majority of the pronounced and fast relaxation effects of the SulfideGSNO interaction in aortic rings.

\subsection{EPR spectra of $\mathrm{MGD}_{2} \mathrm{Fe}^{2+}$ spin trap with the Sulfide/GSNO products}

Since a key reaction product of the interaction of sulfide with nitrosothiols, $\mathrm{SSNO}^{-}$has been shown previously to release $\mathrm{NO}$ as measured by gas phase chemiluminescence and to activate SGC in cellular systems [12], it was of interest to confirm that NO can indeed be generated from longer-lived reaction products (the 'SSNO- mix') using a complementary detection technique. In the present study we chose electron paramagnetic resonance spectroscopy using $\mathrm{MGD}_{2} \mathrm{Fe}^{2+}$ as spin trap. The reagent itself does not have an EPR spectrum (Fig. 6A). After addition of the Sulfide/GSNO reaction mixture to the spin trap a superposition of two different EPR spectra was observed (Fig. 6B). The spectral intensity slowly decreased over time (to $\sim 60 \%$ in $20 \mathrm{~min}$, data not shown). In parallel experiments with GSNO, a stable simple triplet spectrum was detected (Fig. 6C), which could be clearly assigned to NO trapped by $\mathrm{MGD}_{2} \mathrm{Fe}^{2+}$ heme [29]. By comparison of the double integrals of the spectra $\mathrm{B}$ and $\mathrm{C}$, the concentration of $\mathrm{MGD}_{2} \mathrm{Fe}^{2+}$-radical complex in the Sulfide/GSNO product mixture (B) corresponded to about $10 \%$ of GSNO (D). After subtraction of spectrum $C$ from $B$, a single triplet spectrum was observed (Fig. 6D) with slightly different EPR parameters compared with spectrum $C$. From the simulated spectra $\mathrm{C}\left(\mathrm{MGD}_{2} \mathrm{Fe}^{2+}-\mathrm{NO}\right)$ and $\mathrm{D}$ the following spectral parameters were obtained: the isotropic splitting constant $\mathrm{a}_{\mathrm{N}}=1.26 \mathrm{mT}$ and $\mathrm{a}_{\mathrm{N}}=1.19 \mathrm{mT}$ and $\mathrm{g}$-factor $\mathrm{g}=2.040$ and $g=2.037$, respectively. The lower $\mathrm{a}_{\mathrm{N}}$ parameter for the spectrum $D$ versus $C$ indicates that a density of the unpaired electron of the nitrogen nucleus in D was less than in spectrum C. The differences in $\mathrm{g}$-factor values between spectra $\mathrm{C}$ and $\mathrm{D}$ indicate a different coordination of $\mathrm{NO}$ and an NO-containing unknown adduct to the $\mathrm{MGD}_{2} \mathrm{Fe}^{2+}$ spin trap. However, when sulfide was added to spintrapped NO from GSNO (spectrum C), a superposition of two EPR spectra was observed (E), similar to the features of spectrum $B$. This indicates that sulfide, alone or in combination with $\mathrm{NO}$ or the 'SSNO' mix', can influence the structure of the spin trap adduct. Since the NO scavenger cPTIO inhibited the vasorelaxation of GSNO but not that of the 'SSNO- mix' (Fig. 5), we suggest that an NO-containing component(s) of the Sulfide/GSNO reaction may bind to a prosthetic heme on SGC, resulting in enzyme activation and consecutive vasorelaxation and/or release of NO following its binding to heme.

\subsection{Conclusions}

The products of the interaction of sulfide with GSNO, employed in the present study as a model nitrosothiol of potential (patho)physiological significance, was found to exert more pronounced and faster relaxation effects in precontracted aortic rings than the parent compound GSNO. While GSNO and the product(s) of its chemical interaction with sulfide both act via stimulation of sGC, their relaxation profiles were differentially modulated by cPTIO, metHb and $\mathrm{N}$-acetylcysteine, and acidification. This strongly suggests the involvement of more than one product (in the reaction mixture) accounting for sGC activation and vasorelaxation. While $\mathrm{NO}$ is clearly involved in the mechanism of relaxation, HNO appears to be another reactive intermediate. Our results cannot exclude the possibility of a direct SGC activation via an alternative mechanism. Since the products of the Sulfide/GSNO interaction were applied 3 min after mixing (i.e. at a time when no further absorbance changes were seen) relatively long-lived reaction product(s) 

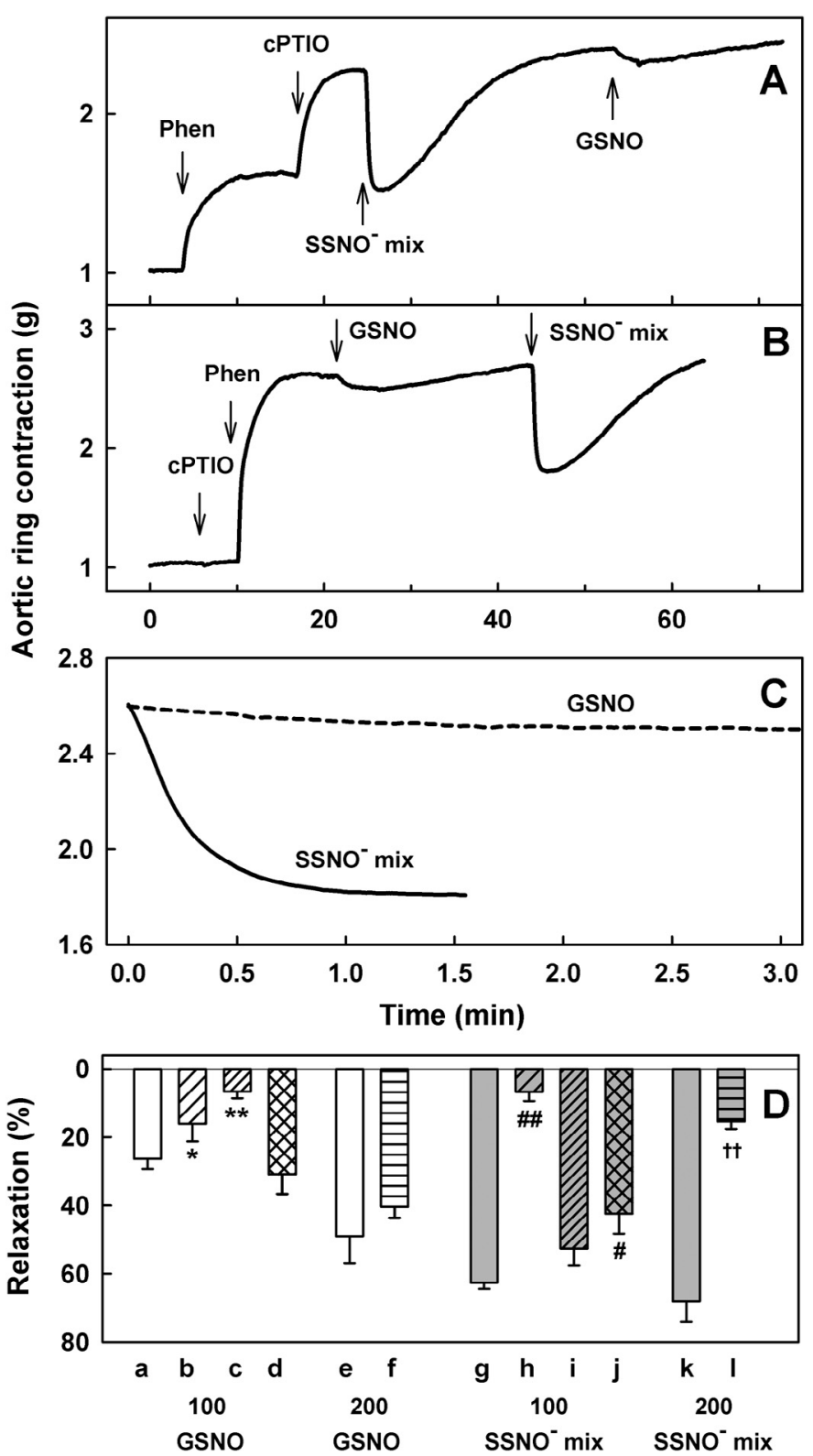

Fig. 5. Representative time-dependent contractile effect of cPTIO $(100 \mu \mathrm{M})$, followed by relaxation to the 'SSNO' mix' and GSNO (both at $100 \mathrm{nM}$ ) in phenylephrine (Phen) precontracted rat aortic rings (A, B). Direct comparison of the time course of relaxation for the 'SSNO- mix' and GSNO (both at $100 \mathrm{nM}$ ) (C). (D) Comparison of the relaxation effect of GSNO (100 nM) alone (a, white), when pH of GSNO solution was decreased to $2-4$ by $\mathrm{HCl}$ before application (b, white, coarse), GSNO in the presence of cPTIO (c, $100 \mu \mathrm{M}$, white, fine coarse) or NAC (d, $1 \mathrm{mM}$, white, crosscoarse). Relaxation effect of GSNO in the absence (e, $200 \mathrm{nM}$, white) and presence of methemoglobin (f, $20 \mu \mathrm{M}$ heme, white, horizontal coarse). Comparison of the relaxation effect of the 'SSNO- mix' (100 nM) alone (g, gray), after adjustment of the $\mathrm{pH}$ to 2-4 by $\mathrm{HCl}$ before application (h, gray, coarse), and the 'SSNO- mix' in the presence of cPTIO (i, $100 \mu \mathrm{M}$, gray, fine coarse) or NAC (j, $1 \mathrm{mM}$, gray, cross-coarse). Comparison of the relaxation effect of the 'SSNO- mix' (200 nM) alone ( $\mathrm{k}$, gray) and in the presence of methemoglobin $(1,20 \mu \mathrm{M}$ heme, gray, horizontal coarse). Effect of $\mathrm{HCl}$, cPTIO and NAC versus 100 nM GSNO was analyzed using the KruskalWallis test followed by the Mann-Whitney $U$ test with Bonferroni correction; ${ }^{*} P<0.05$; ${ }^{* *} P<0.01$. Effect of hemoglobin versus $200 \mathrm{nM}$ GSNO was analyzed using a single Mann-Whitney $U$ test. Effect of $\mathrm{HCl}$, cPTIO and NAC versus $100 \mathrm{nM}$ the 'SSNO- mix' was analyzed using the Kruskal-Wallis test followed by the Mann-Whitney $U$ test with Bonferroni correction; ${ }^{\#} P<0.05$; ${ }^{\# \#} P<0.01$. Effect of hemoglobin versus $200 \mathrm{nM}$ 'SSNO- mix' was analyzed using a single Mann-Whitney $U$ test; ${ }^{\dagger} P<0.01$.

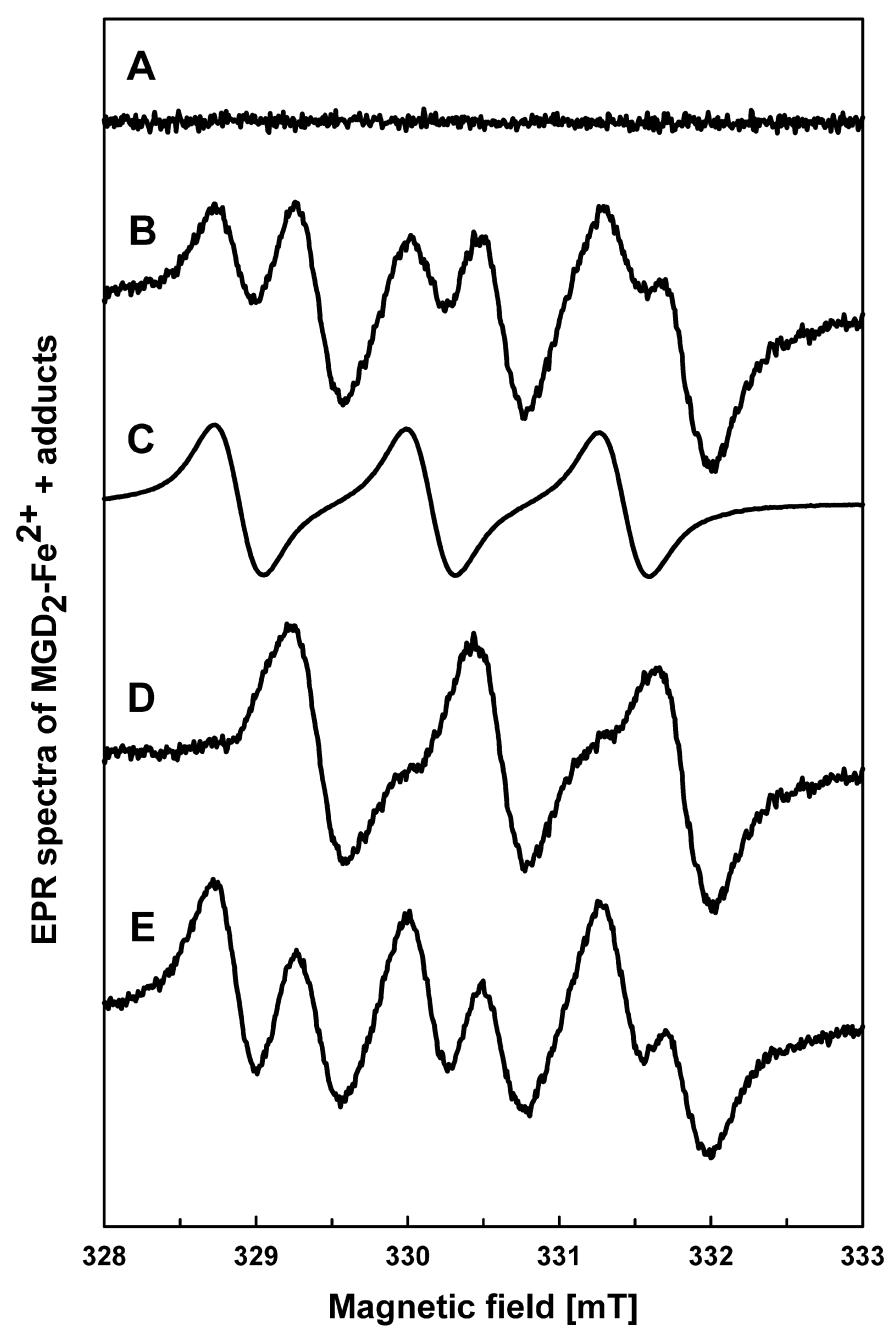

Fig. 6. EPR spectra of spin trap $\mathrm{MGD}_{2} \mathrm{Fe}^{2+}\left(5 \mathrm{mM} \mathrm{MGD}, 1 \mathrm{mM} \mathrm{FeSO}_{4}\right)$ alone (A) and in the presence of the 'SSNO- mix' (B, $0.5 \mathrm{mM})$, GSNO (C, $0.5 \mathrm{mM})$ and substracted spectra B-C (D). EPR spectra in the presence of GSNO $(0.5 \mathrm{mM})$ after addition of $5 \mathrm{mM}$ sulfide (E). The spectra were normalized to similar intensity.

must account for the relaxation observed. These may include $S_{n}$ and SSNO$^{-}[12,13,50]$. Using EPR spectroscopy we confirmed the release of $\mathrm{NO}$ from the reaction mixture, but $\mathrm{SSNO}^{-}$is not known to release HNO. Since sulfide and $S_{n}$, at the concentrations expected to prevail in the reaction mixture, did not induce vasorelaxation under comparable conditions, $\mathrm{SSNO}^{-}$and a yet uncharacterized product capable of generating HNO appear to account for the pronounced relaxation effects of the 'SSNO- mix'. Whether any of this chemistry contributes to the biological cross-talk between sulfide and NO in the cardiovascular system warrants further investigation.

\section{Acknowledgments}

This work was supported by the Slovak Research and Development Agency under contract No. APVV-0074-11, by VEGA 2/0050/ 13, 1/0289/12 and 2/0074/14, and by BMBS COST Action BM1005 (http://www.gasotransmitters.eu). Financial support from FP7PEOPLE-2010-RG (Marie Curie International Reintegration Grant; grant No.: PIRG08-GA-2010-277006) and the Hungarian National Science Foundation (OTKA; grant No.: K 109843) for P.N. is greatly acknowledged. 


\section{References}

[1] R. Wang, Physiological implications of hydrogen sulfide: a whiff exploration that blossomed, Physiol. Rev. 92 (2012) 791-896.

[2] J.S. Stamler, Redox signaling: nitrosylation and related target interactions of nitric oxide, Cell 78 (1994) 931-936.

[3] M. Ishigami, K. Hiraki, K. Umemura, Y. Ogasawara, K. Ishii, H. Kimura, A source of hydrogen sulfide and a mechanism of its release in the brain, Antioxid. Redox Signal. 11 (2009) 205-214.

[4] F. Seel, M. Wagner, Über die Umsetzung von Polysulfiden mit Stickstoffmonoxid in nichtwäßrigen Lösungsmitteln - Nitrosodisulfide, Z. Naturforsch 40 (1985) $762-764$.

[5] F. Seel, M. Wagner, Über die Umsetzung von Sulfiden mit Stickstoffmonoxid in Wäßrigen Lösungen, Z. Anorg. Allg. Chem. 558 (1988) 189-192.

[6] A.P. Munro, D.L.H. Williams, Reactivity of sulfur nucleophiles towards S-nitrosothiols, J. Chem. Soc. Perkin Trans. 2 (2000) 1794-1797.

[7] M. Whiteman, L. Li, I. Kostetski, S.H. Chu, J.L. Siau, M. Bhatia, et al., Evidence for the formation of a novel nitrosothiol from the gaseous mediators nitric oxide and hydrogen sulphide, Biochem. Biophys. Res. Commun. 343 (2006) 303-310.

[8] K. Ondrias, A. Stasko, S. Cacanyiova, Z. Sulova, O. Krizanova, F. Kristek, et al., $\mathrm{H}_{2} \mathrm{~S}$ and $\mathrm{HS}^{-}$donor NaHS releases nitric oxide from nitrosothiols, metal nitrosyl complex, brain homogenate and murine L1210 leukaemia cells, Pflugers Arch. 457 (2008) 271-279.

[9] A. Bertova, S. Cacanyiova, F. Kristek, O. Krizanova, K. Ondrias, Z. Tomaskova, The hypothesis of the main role of $\mathrm{H}_{2} \mathrm{~S}$ in coupled sulphide-nitroso signalling pathway, Gen. Physiol. Biophys. 29 (2010) 402-410.

[10] M.R. Filipovic, J. Miljkovic, T. Nauser, M. Royzen, K. Klos, T. Shubina, et al., Chemical characterization of the smallest S-nitrosothiol, HSNO; cellular cross-talk of $\mathrm{H}_{2} \mathrm{~S}$ and S-nitrosothiols, J. Am. Chem. Soc. 134 (2012) 12016-12027.

[11] M. Grman, A. Misak, C. Jacob, Z. Tomaskova, A. Bertova, T. Burkholz, et al., Low molecular thiols, $\mathrm{pH}$ and $\mathrm{O}_{2}$ modulate $\mathrm{H}_{2} \mathrm{~S}$-induced S-nitrosoglutathione decomposition - NO release, Gen. Physiol. Biophys. 32 (2013) 429-441.

[12] M.M. Cortese-Krott, B.O. Fernandez, J.L. Santos, E. Mergia, M. Grman, P. Nagy, et al., Nitrosopersulfide $\left(\mathrm{SSNO}^{-}\right)$accounts for sustained NO bioactivity of S-nitrosothiols following reaction with sulfide, Redox Biol. 2 (2014) 234-244.

[13] M. Eberhardt, M. Dux, B. Namer, J. Miljkovic, N. Cordasic, C. Will, et al., $\mathrm{H}_{2} \mathrm{~S}$ and NO cooperatively regulate vascular tone by activating a neuroendocrine HNO-TRPA1-CGRP signalling pathway, Nat. Commun. 5 (2014) 4381

[14] H. Kimura, Hydrogen sulfide and polysulfides as biological mediators, Molecules 19 (2014) 16146-16157.

[15] R. Hosoki, N. Matsuki, H. Kimura, The possible role of hydrogen sulfide as an endogenous smooth muscle relaxant in synergy with nitric oxide, Biochem. Biophys. Res. Commun. 237 (1997) 527-531.

[16] M.Y. Ali, C.Y. Ping, Y.Y. Mok, L. Ling, M. Whiteman, M. Bhatia, et al., Regulation of vascular nitric oxide in vitro and in vivo; a new role for endogenous hydrogen sulphide?, Br. J. Pharmacol. 149 (2006) 625-634

[17] H. Robinson, S. Wray, A new slow releasing, $\mathrm{H}_{2} \mathrm{~S}$ generating compound, GYY4137 relaxes spontaneous and oxytocin-stimulated contractions of human and rat pregnant myometrium, PLoS ONE 7 (2012) e46278.

[18] R. Sidhu, M. Singh, G. Samir, R.J. Carson, L-cysteine and sodium hydrosulphide inhibit spontaneous contractility in isolated pregnant rat uterine strips in vitro, Pharmacol. Toxicol. 88 (2001) 198-203.

[19] A. Mijuskovic, Z. Orescanin-Dusic, A. Nikolic-Kokic, M. Slavic, M.B. Spasic, I. Spasojevic, et al., Comparison of the effects of methanethiol and sodium sulphide on uterine contractile activity, Pharmacol. Rep. 66 (2014) 373-379.

[20] M.R. Filipovic, M. Eberhardt, V. Prokopovic, A. Mijuskovic, Z. Orescanin-Dusic, P. Reeh, et al., Beyond $\mathrm{H}_{2} \mathrm{~S}$ and $\mathrm{NO}$ interplay: hydrogen sulfide and nitroprusside react directly to give nitroxyl (HNO). A new pharmacological source of HNO, J. Med. Chem. 56 (2013) 1499-1508.

[21] H. Kimura, Signaling molecules: hydrogen sulfide and polysulfide, Antioxid. Redox Signal doi:10.1089/ars.2014.5869.

[22] H. Kimura, Signaling of hydrogen sulfide and polysulfides, Antioxid. Redox Signal doi:10.1089/ars.2014.6082.

[23] R. Greiner, Z. Palinkas, K. Basell, D. Becher, H. Antelmann, P. Nagy, et al., Polysulfides link $\mathrm{H}_{2} \mathrm{~S}$ to protein thiol oxidation, Antioxid. Redox Signal. 19 (2013) 1749-1765.

[24] T. Okawa, A. Sato, A.S. Syal, Y.P. Vedernikov, G.R. Saade, R.E. Garfield, Effects of nitric oxide donors on non-pregnant and pregnant rat uterine and aortic smooth muscle, Fukushima J. Med. Sci. 49 (2003) 23-32.

[25] R.A. Word, T.L. Cornwell, Regulation of cGMP-induced relaxation and cGMPdependent protein kinase in rat myometrium during pregnancy, Am. J. Physiol. 274 (1998) C748-C756.
[26] P. Nagy, Z. Palinkas, A. Nagy, B. Budai, I. Toth, A. Vasas, Chemical aspects of hydrogen sulfide measurements in physiological samples, Biochim. Biophys. Acta 2014 (1840) 876-891.

[27] P. Nagy, C.C. Winterbourn, Rapid reaction of hydrogen sulfide with the neutrophil oxidant hypochlorous acid to generate polysulfides, Chem. Res. Toxicol. 23 (2010) 1541-1543.

[28] F.K. Marcondes, F.J. Bianchi, A.P. Tanno, Determination of the estrous cycle phases of rats: some helpful considerations, Braz. J. Biol. 62 (2002) 609-614.

[29] A.F. Vanin, X. Liu, A. Samouilov, R.A. Stukan, J.L. Zweier, Redox properties of iron-dithiocarbamates and their nitrosyl derivatives: implications for their use as traps of nitric oxide in biological systems, Biochim. Biophys. Acta 1474 (2000) 365-377.

[30] P. Patel, M. Vatish, J. Heptinstall, R. Wang, R.J. Carson, The endogenous production of hydrogen sulphide in intrauterine tissues, Reprod. Biol. Endocrinol. 7 (2009) 10.

[31] H. Karaki, K. Murakami, H. Nakagawa, N. Urakawa, Nitroglycerine-induced biphasic relaxation in vascular smooth muscle of rat aorta, Br. J. Pharmacol. 81 (1984) 387-392.

[32] S.A. Waldman, R.M. Rapoport, R. Ginsburg, F. Murad, Desensitization to nitroglycerin in vascular smooth muscle from rat and human, Biochem. Pharmacol. 35 (1986) 3525-3531.

[33] Y.H. Lee, S.I. Kang, D.S. Ahn, H.Y. Lee, E.J. Choi, B.S. Kang, Effects of mastoparan on a vascular contractility in rabbit aorta, Yonsei Med. J. 36 (1995) 262-270.

[34] R.A. Cohen, R.M. Weisbrod, M. Gericke, M. Yaghoubi, C. Bierl, V.M. Bolotina, Mechanism of nitric oxide-induced vasodilatation: refilling of intracellular stores by sarcoplasmic reticulum $\mathrm{Ca}^{2+}$ ATPase and inhibition of store-operated $\mathrm{Ca}^{2+}$ influx, Circ. Res. 84 (1999) 210-219.

[35] K.K. Bradley, I.L. Buxton, J.E. Barber, T. McGaw, M.E. Bradley, Nitric oxide relaxes human myometrium by a cGMP-independent mechanism, Am. J. Physiol. 275 (1998) C1668-C1673.

[36] M.R. Al-Magableh, J.L. Hart, Mechanism of vasorelaxation and role of endogenous hydrogen sulfide production in mouse aorta, Naunyn Schmiedebergs Arch. Pharmacol. 383 (2011) 403-413.

[37] P. Ariyaratnam, M. Loubani, A.H. Morice, Hydrogen sulphide vasodilates human pulmonary arteries: a possible role in pulmonary hypertension?, Microvasc. Res. 90 (2013) 135-137.

[38] F. Murad, Shattuck Lecture. Nitric oxide and cyclic GMP in cell signaling and drug development, N. Engl. J. Med. 355 (2006) 2003-2011.

[39] S. Goldstein, A. Russo, A. Samuni, Reactions of PTIO and carboxy-PTIO with ${ }^{\circ} \mathrm{NO}$, $\mathrm{NO}_{2}$, and $\mathrm{O}_{2}{ }^{\bullet-}$, J. Biol. Chem. 278 (2003) 50949-50955.

[40] H.W. Kim, A.G. Greenburg, Hemoglobin mediated contraction of the isolated rat thoracic aorta: why is precontraction necessary?, Artif. Cells Blood Substit. Immobil. Biotechnol. 33 (2005) 27-36.

[41] G.Y. Ko, P.T. Kelly, Nitric oxide acts as a postsynaptic signaling molecule in calcium/calmodulin-induced synaptic potentiation in hippocampal CA1 pyramidal neurons, J. Neurosci. 19 (1999) 6784-6794.

[42] M. Catalá, F. Gasulla, A.E. Pradas del Real, F. García-Breijo, J. Reig-Armiñana, E Barreno, Fungal-associated NO is involved in the regulation of oxidative stress during rehydration in lichen symbiosis, BMC Microbiol. 10 (2010) 297.

[43] J.C. Wanstall, T.K. Jeffery, A. Gambino, F. Lovren, C.R. Triggle, Vascular smooth muscle relaxation mediated by nitric oxide donors: a comparison with acetylcholine, nitric oxide and nitroxyl ion, Br. J. Pharmacol. 134 (2001) 463472 .

[44] J.C. Irvine, J.L. Favaloro, R.E. Widdop, B.K. Kemp-Harper, Nitroxyl anion donor Angeli's salt, does not develop tolerance in rat isolated aortae, Hypertension 49 (2007) 885-892.

[45] J.L. Favaloro, B.K. Kemp-Harper, Redox variants of $\mathrm{NO}$ (NO and HNO) elicit vasorelaxation of resistance arteries via distinct mechanisms, Am. J. Physiol. Heart Circ. Physiol. 296 (2009) H1274-H1280.

[46] A.A. Bobko, V.V. Khramtsov, Mechanistic studies of oxidative decomposition of Angeli's salt and PAPA NONOate, Nitric Oxide 40 (2014) 92-98.

[47] R.Z. Pino, M. Feelisch, Bioassay discrimination between nitric oxide (NO) and nitroxyl (NO-) using L-cysteine, Biochem. Biophys. Res. Commun. 201 (1994) 54-62.

[48] M.E. Shoman, J.F. DuMond, T.S. Isbell, J.H. Crawford, A. Brandon, J. Honovar, et al. Acyloxy nitroso compounds as nitroxyl (HNO) donors: kinetics, reactions with thiols, and vasodilation properties, J. Med. Chem. 54 (2011) 1059-1070.

[49] M.P. Doyle, S.N. Mahapatro, R.D. Broene, J.K. Guy, Oxidation and reduction of hemoproteins by trioxodinitrate(II). The role of nitrosyl hydride and nitrite, J. Am. Chem. Soc. 110 (1988) 593-599.

[50] Y. Kimura, Y. Mikami, K. Osumi, M. Tsugane, J. Oka, H. Kimura, Polysulfides are possible $\mathrm{H}_{2} \mathrm{~S}$-derived signaling molecules in rat brain, FASEB J. 27 (2013) 2451-2457. 